\title{
Molecular evolution of the keratin associated protein gene family in mammals, role in the evolution of mammalian hair Dong-Dong $\mathrm{Wu}^{1,3}$, David M Irwin ${ }^{4,5}$ and Ya-Ping Zhang*1,2
}

\begin{abstract}
Address: ${ }^{1}$ State Key Laboratory of Genetic Resources and Evolution, Kunming Institute of Zoology, Chinese Academy of Sciences, Kunming, PR China, ${ }^{2}$ Laboratory for Conservation and Utilization of Bio-resource, Yunnan University, Kunming 650091, PR China, ${ }^{3} \mathrm{Graduate}$ School of the Chinese Academy of Sciences, Beijing, PR China, ${ }^{4}$ Department of Laboratory Medicine and Pathobiology, University of Toronto, Ontario, Canada and ${ }^{5}$ Banting and Best Diabetes Centre, University of Toronto, Ontario, Canada
\end{abstract}

Email: Dong-Dong Wu - dongdongw86@yahoo.com.cn; David M Irwin - david.irwin@utoronto.ca; Ya-Ping Zhang* - zhangyp@mail.kiz.ac.cn

* Corresponding author

Published: 23 August 2008

BMC Evolutionary Biology 2008, 8:24I doi:10.1 I86/I47|-2/48-8-24I

This article is available from: http://www.biomedcentral.com/I47I-2/48/8/24|

(C) 2008 Wu et al; licensee BioMed Central Ltd.

This is an Open Access article distributed under the terms of the Creative Commons Attribution License (http://creativecommons.org/licenses/by/2.0), which permits unrestricted use, distribution, and reproduction in any medium, provided the original work is properly cited.
Received: 30 May 2008

Accepted: 23 August 2008

\begin{abstract}
Background: Hair is unique to mammals. Keratin associated proteins (KRTAPs), which contain two major groups: high/ultrahigh cysteine and high glycine-tyrosine, are one of the major components of hair and play essential roles in the formation of rigid and resistant hair shafts.

Results: The KRTAP family was identified as being unique to mammals, and near-complete KRTAP gene repertoires for eight mammalian genomes were characterized in this study. An expanded KRTAP gene repertoire was found in rodents. Surprisingly, humans have a similar number of genes as other primates despite the relative hairlessness of humans. We identified several new subfamilies not previously reported in the high/ultrahigh cysteine KRTAP genes. Genes in many subfamilies of the high/ultrahigh cysteine KRTAP genes have evolved by concerted evolution with frequent gene conversion events, yielding a higher GC base content for these gene sequences. In contrast, the high glycine-tyrosine KRTAP genes have evolved more dynamically, with fewer gene conversion events and thus have a lower GC base content, possibly due to positive selection.

Conclusion: Most of the subfamilies emerged early in the evolution of mammals, thus we propose that the mammalian ancestor should have a diverse KRTAP gene repertoire. We propose that hair content characteristics have evolved and diverged rapidly among mammals because of rapid divergent evolution of KRTAPs between species. In contrast, subfamilies of KRTAP genes have been homogenized within each species due to concerted evolution.
\end{abstract}

\section{Background}

The availability of the rapidly increasing number of genome sequences provides opportunities for investigators to study evolutionary patterns that potentially account for morphological characteristics, and suggest the genetic basis for variation in phenotypes. In particular, gene families in which duplications, rate variation and pseudogenization occur frequently are likely involved in functional innovation and adaptation [1]. Examples of such gene families are those involved in the perception systems, for example, the odorant receptors $[2-4]$, the vomeronasal receptors [5-8], and the sweet/umami and bitter receptors [9-12]. Furthermore, these studies should facilitate our understanding of the general evolutionary trends in genomic complexity and lineage-specific adaptation [1]. Here, we studied the evolutionary patterns of the 
keratin associated protein (KRTAP) gene family, whose encoded proteins are major components of hair, with the goal of revealing the underlying basis for unique mammalian hair and its phenotypic diversity.

Hair is a unique character found on all mammals, but not on other animals, where it plays a crucial role in the retention of heat within these homoiotherms and presumably contributed significantly to the rapid radiation of mammals and their rise to become the dominant terrestrial vertebrate [13]. Other functions of hair include sexual dimorphism, attraction of mates, and protection of skin [14]. An interesting event in hair evolution has been its loss in humans $[15,16]$, however; humans actually have a similar density of hair follicles to that seen in apes [15]. Comparative studies have concluded that hair presents similar structure and modality of growth throughout mammals [17-19]. For example, the overall ultrastructure of hair and the distribution of keratins in monotremes are similar to that of marsupial and placental mammals [18], and the localization of acidic and basic keratins in marsupial hairs is similar to that in placentals [19]. However, most studies have focused on keratins rather than the keratin associated proteins.

The major components of hair are alpha-keratins and keratin associated proteins, each of which are encoded by multigene families. The alpha-keratins include two multigene subfamilies, type I (acidic) and type II (basic) $[20,21]$, and form the intermediate filament cytoskeleton of all epithelia providing stability against stress [22]. In humans, the alpha-keratin gene family has been extensively studied demonstrating that there are 54 functional genes that are clustered on chromosomes 12q13.13 and $17 \mathrm{q} 21.2$ that show differing expression patterns during hair development [23]. Hair keratins form an intermediate filament (IF) network by co-polymerization of type I and type II members, in trichocytes, which are cells that populate the central hair-forming compartment of the anagen hair follicle $[24,25]$. In the hair cortex, hair keratins IFs are embedded in an in interfilamentous matrix, which consists of hair keratin-associated proteins (KATAP, usually abbreviated as KAP) [26]. KRTAP contains two major groups: high/ultrahigh cysteine (HS) and high glycine-tyrosine (HGT) that are considered to have originated independently, and are essential for the formation of rigid and resistant hair shafts through their extensive disulfide bond cross-linking with the abundant cysteine residues of hair keratins or hydrophobic interactions with keratins [23,26-28]. The genes have been grouped into 27 subfamilies, termed KRTAP1 to KRTAP27, based upon phylogeny $[23,29]$. In humans, about 100 KRTAP genes are identified, that are in five tandemly arranged clusters (chromosomal regions 11p15.5, 11q13.4, 17q21.2, 21q22.1, and 21q22.3) [30-34]. Previous research on
KRTAP genes has focused on their function and expression, with little emphasis on the origin and evolution of this gene family. Here, we investigate the evolution of the KRTAP gene family, including phylogeny and classification, and the mechanisms involved, such as gene duplication, gene conversion, in our endeavor to resolve hair's evolutionary history and to explain the diversity observed in extant mammals. We find different repertoires among mammals which potentially explain the differing hair features of different lineages. An expanded KRTAP gene repertoire was found in rodents. Surprisingly, despite the lack of hair, human had a similar number of genes with other primates. Large-scale gene conversion events were detected in high cysteine KRTAP but fewer in high glycine/ tyrosine, and the latter genes evolve more dynamically. Compared to the conserved structure and modality of keratins within mammals, the significant divergence of characteristics of hair among placental, marsupial and monotreme species is likely due to interspecific divergence of KRTAP sequences.

\section{Results}

\section{Inventory of KRTAP genes in mammals}

The recent rapid increase in the availability of comparative genomic data is facilitating the illumination of evolutionary features of organisms. Particularly, mammals are well represented with data from: placental mammals including primates - human [35], chimpanzee [36] and rhesus macaque [37]; rodents - mouse [38] and rat [39]; carnivore - dog [40]; a marsupial, the opossum [41]; and a monotreme, the duck-billed platypus [42].

Some gene sequences in GenBank http:// www.ncbi.nlm.nih.gov have been submitted independently by several researchers. KRTAP genes have been shown to have size polymorphism within populations [43-45], and sequences from different individuals at these loci are diverse and may not align well. For instance, we identified that a KRTAP gene cluster in Contig: NT 113931 actually corresponds to the KRTAP region on Chr17 of the human genome, except that it differs in sequence length for several KRTAP genes. Therefore, we removed the genes from Contig: NT 113931 from our analyses. Furthermore, since many of the draft genome sequences were generated by whole genome shotgun assembly, we took care to identify redundant KRTAP sequences and excluded these from our analysis.

Since KRTAP genes are clustered as tandem arrays at just a few chromosomal locations and the genome sequences have high coverage (except platypus), we should be able to obtain near-complete and non-redundant KRTAP gene inventories from these mammalian genomes after indepth screening and examination (summarized in additional file 1). In contrast to the mammalian genomes, we 
were unable to identify any KRTAP-like sequences from the chicken, lizard, Xenopus tropicalis or zebrafish genomes. We also note that the keratin associated protein 10-4 annotated in the chicken genome in GenBank (gene id: 425968) is actually an oncogenic transcription factor (JAC), and is not KRTAP-like nor has homology with any mammalian KRTAP sequences. As an alternative strategy to identify KRTAP genes in the chicken, we used Mapviewer from NCBI http://www.ncbi.nlm.nih.gov/ mapview/ to identify genes flanking the KRTAP gene clusters in mammals and searched the chicken genome using BLAST to identify orthologous genomic regions. While conserved synteny of the flanking genes was observed within the chicken genome, KRTAP-like genes could not be found. These results indicate that the KRTAP gene clusters are unique to mammals and have been inserted into in the ancestral mammalian genome.

We classified our identified KRTAP gene sequences into two categories, intact and pseudo-genes. Pseudogenes are defined as coding sequences that are disrupted by frameshifts and/or stop codons. In placental mammals, rodents appear to contain an expanded KRTAP gene repertoire with a lower level of pseudogenization relative to other mammals both in high (including ultrahigh) cysteine and high glycine KRTAPs (fig. 1). Surprisingly, although humans have the lowest number of intact genes
(101) and the highest number of pseudogenes (21, 17.2\% of total number), the complete repertoire (122) is still similar in number to that of other mammals. Potentially, changes in the levels of expression of KRTAP genes may account for the relative hairlessness of humans. Opossum has a slightly larger repertoire of genes, and the repertoire in platypus is probably much larger than that we reported, since a more complete genome sequence is required to accurately define gene number.

\section{Classification of KRTAP gene family, and tandem cluster in the genomes}

Without the influence of evolutionary constraint, pseudogenes evolve faster then functional genes. Accordingly, substitution bias could generate errors in constructing phylogenies; therefore all pseudogenes were excluded from our preliminary analysis on subfamily classification. The high levels of divergence between species and/or subgroups and the homogenization within them caused by frequent gene conversion (see following text), may also introduce a bias into the construction of a phylogeny of all of the high cysteine KRTAPs. To circumvent this problem, we first constructed a neighbor-joining tree of just the human high cysteine KRTAP protein sequences, and used this phylogeny to identify subfamilies (Additional file 2: figure 1). The majority of genes for each subfamily were found as subfamily-specific tandem cluster in the

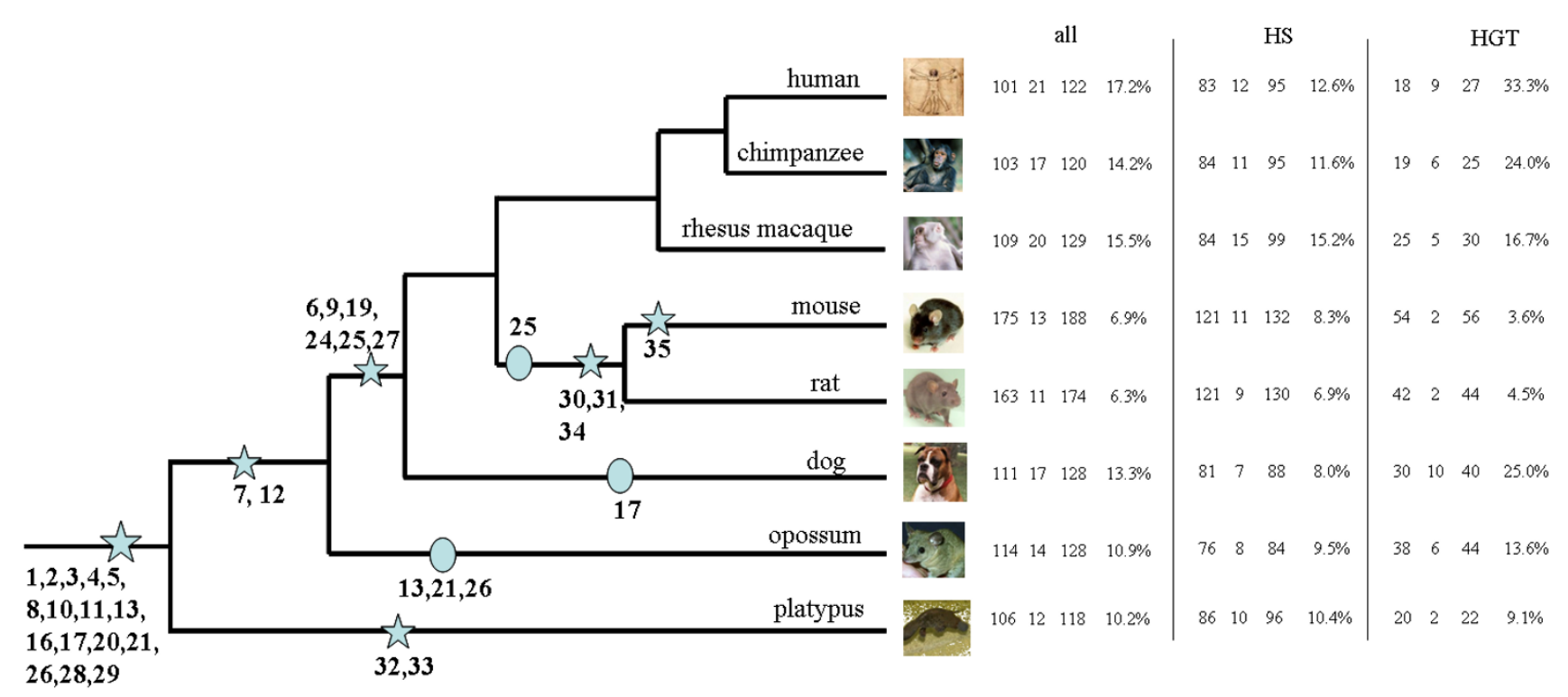

\section{Figure I}

Summary of the evolution of the KRTAP gene repertoires in eight mammals. Major events in the evolution of the KRTAP gene family are summarized. The number of KRTAP genes in each species is indicated on the right with "all", "HS", and "HGT" indicating patterns for all, high/ultrahigh cysteine, and high glycine-tyrosine KRTAPs, respectively. The columns represent the numbers of intact, interrupted and all genes and the percentage of pseudogenization calculated as the ratio of number of disrupted gene to all genes, for each of the categories of genes. Stars in the phylogeny indicate the origin of subfamilies, while circles indicate losses. 
genome (Additional file 2: figure 1 and Additional file 1). Genes with close relationships in our phylogeny tended to be most closely linked in the genome. This positive correlation between phylogeny and chromosomal location has previously been observed in several other gene families $[46,47]$. Thus we used chromosomal location in combination with phylogeny to refine our subfamily classification. In addition we also considered amino acid sequence composition to generate our final classification. Next we constructed phylogenies of all of the high cysteine KRTAPs for each species alone (Additional file 2: figures 2-8), or combined with the human sequences (Additional file 2: figures 9-15), as well as a phylogeny of the combined mouse and rat sequences (Additional file 2: figure 16). From these phylogenies, together with chromosomal location and amino acid composition, we could identify several new subfamilies not reported previously, which we name subfamilies 28-35. Additionally, we grouped the previously characterized subfamilies 14 and 15 into subfamily 13 based on our phylogeny. In a similar manner, we grouped the glycine-tyrosine rich KRTAPs into 6 subfamilies (subfamilies $6,7,8,19,20$ and 21) based on the phylogenetic tree (fig. 2, and Additional file 2: figure 17). The previously defined human subfamily 22 was combined with subfamily 19 . Our recommendations have been endorsed by the HUGO Gene Nomenclature Committee [48].

Our phylogeny of intact genes indicated that genes within subfamilies are clustered in the genomic location (fig. 3, and Additional file 1). When pseudogenes were included in the phylogenetic analysis they were also found to be most closely related to their genomic neighbors. To classify interrupted genes that were annotated in unmapped (i.e., unassembled) genomic locations, BLAST was performed against the non-redundant database in GenBank to identify the best hit KRTAP genes, and phylogenetic classification of these were used to help classify the pseudogenes.

It should be noted that there is typically only about one gene per species for subfamilies 16, 24-27, and 29 (table $1)$, thus, these subfamilies were not used for our subsequent analysis for gene conversion.

\section{Chromosome distribution of KRTAP}

KRTAP genes are distributed mainly at five genomic regions in placental and marsupial genomes: Cluster 1 contains genes from subfamilies KRTAP 1, 2, 3, 4, 9, 17, 16 , and 29. Cluster 2 contains genes from subfamilies 13, 24-27 and all glycine-tyrosine rich KRTAPs. Cluster 3 possesses genes from subfamilies 10 and 12. Cluster 4 encodes genes of subfamily 28 . Cluster 5 corresponds to genes of subfamily 5 (fig. 3 ). Some variation in gene distribution is observed in some species. In rodents, the new subfamilies 30 and 31 have been inserted into the genomic locations of subfamilies 4 and 9 respectively. Paralogous KRTAP gene clusters have been mapped to human chromosomes $11 \mathrm{q} 13$ and chr11p15, with genes residing in these two clusters intermingled in the phylogeny (fig. 3.). Thus suggests that the KRTAP gene cluster at $11 \mathrm{q} 13$ is derived from $11 \mathrm{p} 15$ potentially representing a segmental duplication. The new chromosome 11q13 gene cluster is unique to primates as an orthologous region is also found in the chimpanzee and rhesus macaque genomes but not in others mammals (additional file 1). In a similar manner the dog genome has generated a new cluster on chromosome 31 that includes three genes, one from subfamily 10 and two from subfamily 12 . Similar mechanisms for the origin of new genes at new genomic locations have been observed for other gene families $[49,50]$.

\section{Amino acid composition comparison of KRTAP subfamilies} Previous research has classified the keratin associated proteins by their amino acid composition into three major groups: high-sulfur ( $16-30 \%$ cysteine), ultra-high sulfur (> 30\% cysteine), and high-glycine/tyrosine [26]. Subfamilies 1, 2, 3, 10, 12, 16, 29 and 31, belong to the highsulfur group; subfamilies 4, 5, 9, 17, 28, 30, 32 and 33 are ultra-high sulfur (table 2). Many high cysteine genes also have a high content of serine. Interestingly, subfamilies $11,13,24-27,29,34$ and 35 have high serine content but relative low cysteine (table 2 ). The newly identified subfamilies 28 and 30, for which there is no functional or expression data, have the highest cysteine content (39.5\%, $50.1 \%$ respectively).

\section{Concerted evolution yields a high GC (Guanine and Cytosine) content in high cysteine KRTAP gene family}

The evolutionary patterns observed in a multigene family can be attributed to two traditional models: concerted evolution and the birth-and-death process [47]. Members of a gene family under concerted evolution evolve in a concerted manner rather than independently, as a mutation occurring in one member will spread through the entire gene family by the repeated occurrence of unequal crossover and/or gene conversion [47]. Concerted evolution therefore results in the distance between pairs of genes remaining low. Considering the abundant speciesspecific clusters in the KRTAP gene phylogeny, many should be candidates for concerted evolution. Gene conversion plays a parallel role to unequal crossing over, with their major difference being that the latter can change the copy number of a gene; however, it is difficult to distinguish between these two mechanisms.

We identified potential gene conversion events within each subfamily using the methods implemented in the GeneConv program [51] which identifies identical frag- 


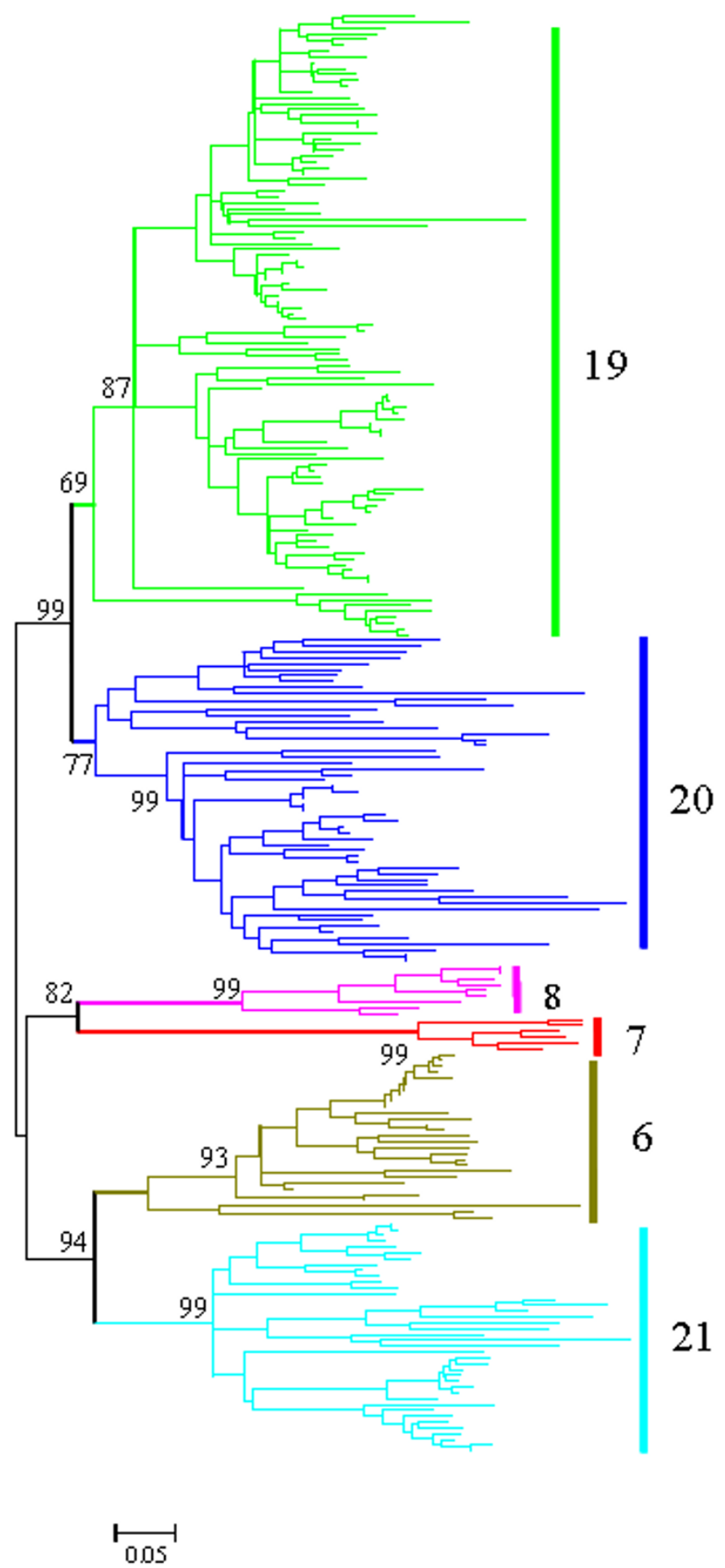

Figure 2

Phylogenetic tree of high glycine-tyrosine KRTAP genes of all mammals. Simplified phylogeny of all of the high glycine-tyrosine KRTAP genes generated by the neighbor-joining algorithm using p-distances. Genes of each subfamily are represented by different colors. Numbers on branches are the reliabilities of the branches which are calculated by interior branch tests with I,000 replications. The bars indicate six subfamilies $(6,7,8,19,20$ and 2I) of HGT-KRTAP genes. 


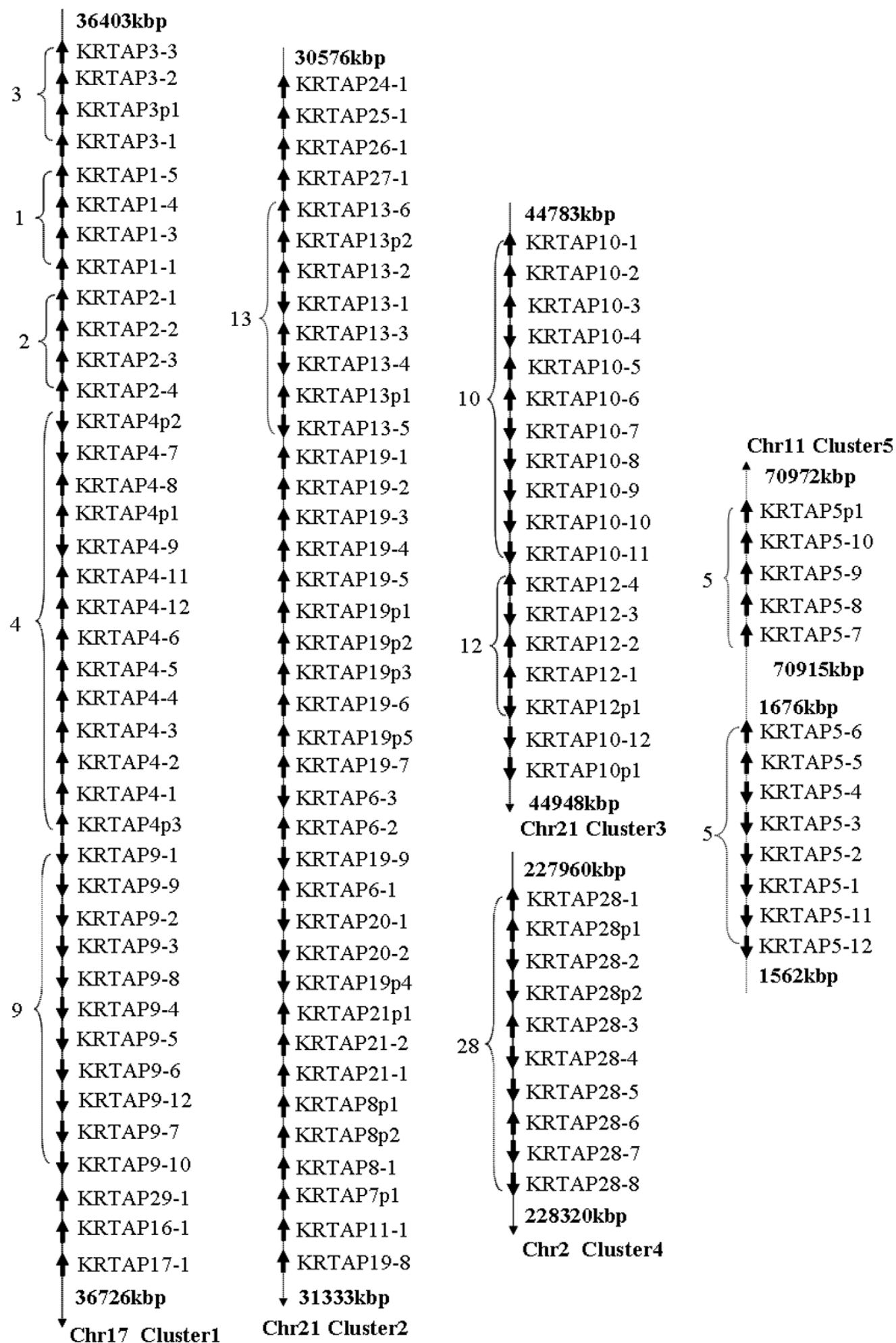

\section{Figure 3}

Summary of the chromosomal distribution of KRTAP genes in the human genomes. The relative genomic location of each KRTAP gene is shown for chromosomes 2, II, 17 and 21 . Each gene, and distances between genes are not to scale. Arrowheads indicate the direction of transcription. The clusters are also labeled. 
Table I: Numbers of KRTAP gene in each subfamily in eight mammalian species.

\begin{tabular}{|c|c|c|c|c|c|c|c|c|c|}
\hline & subfamily & human & chimpanzee & rhesus macaque & mouse & rat & $\operatorname{dog}$ & opossum & platypus \\
\hline \multicolumn{10}{|l|}{ HS-KRTAP } \\
\hline & I & $4(0)$ & $4(0)$ & $4(0)$ & $4(0)$ & $4(0)$ & $4(0)$ & $4(0)$ & $4(1)$ \\
\hline & 2 & $4(0)$ & $4(0)$ & $4(1)$ & $4(0)$ & $4(0)$ & $4(0)$ & $4(0)$ & $4(0)$ \\
\hline & 3 & $4(1)$ & $4(0)$ & $4(1)$ & $4(0)$ & $4(0)$ & $4(0)$ & $4(0)$ & $5(0)$ \\
\hline & 4 & $14(3)$ & $14(3)$ & $14(5)$ & $18(2)$ & $16(3)$ & $8(0)$ & $30(6)$ & $19(3)$ \\
\hline & 5 & $14(2)$ & $15(2)$ & $18(1)$ & $18(0)$ & $20(1)$ & $14(2)$ & $9(0)$ & $7(1)$ \\
\hline & 9 & $\mathrm{II}(0)$ & $I I(I)$ & $9(2)$ & $7(2)$ & $7(2)$ & $7(1)$ & 0 & 0 \\
\hline & 10 & $13(1)$ & $13(1)$ & $13(0)$ & $14(0)$ & $14(0)$ & $14(0)$ & $13(0)$ & $12(0)$ \\
\hline & 11 & $\mathrm{I}(0)$ & $\mathrm{I}(0)$ & $\mathrm{I}(0)$ & $\mathrm{I}(0)$ & $\mathrm{I}(0)$ & $\mathrm{I}(0)$ & $\mathrm{I}(0)$ & $I(0)$ \\
\hline & 12 & $5(1)$ & $5(1)$ & $5(1)$ & $5(0)$ & $6(0)$ & $7(0)$ & $6(2)$ & 0 \\
\hline & 13 & $8(2)$ & $6(2)$ & $9(3)$ & $14(4)$ & $13(3)$ & $9(3)$ & 0 & $5(0)$ \\
\hline & 16 & $I(0)$ & $\mathrm{I}(0)$ & $I(0)$ & $I(0)$ & $I(0)$ & $\mathrm{I}(0)$ & $I(0)$ & $I(0)$ \\
\hline & 17 & $\mathrm{I}(0)$ & $\mathrm{I}(0)$ & I (0) & I (0) & $\mathrm{I}(0)$ & 0 & $I(0)$ & $I(0)$ \\
\hline & 24 & $\mathrm{I}(0)$ & $\mathrm{I}(0)$ & $I(0)$ & $\mathrm{I}(0)$ & $I(0)$ & $\mathrm{I}(0)$ & 0 & 0 \\
\hline & 25 & $\mathrm{I}(0)$ & $\mathrm{I}(0)$ & I(I) & 0 & 0 & $\mathrm{I}(0)$ & 0 & 0 \\
\hline & 26 & $\mathrm{I}(0)$ & $\mathrm{I}(0)$ & $2(0)$ & $I(0)$ & $\mathrm{I}(0)$ & $\mathrm{I}(0)$ & 0 & $3(0)$ \\
\hline & 27 & $I(0)$ & $I(0)$ & $I(0)$ & $I(0)$ & $I(0)$ & $\mathrm{I}(0)$ & 0 & 0 \\
\hline & 28 & $10(2)$ & $\mathrm{II}(\mathrm{I})$ & $10(0)$ & $13(0)$ & $12(0)$ & $10(0)$ & $10(0)$ & $9(0)$ \\
\hline & 29 & $I(0)$ & $I(0)$ & $I(0)$ & $I(0)$ & $I(0)$ & $\mathrm{I}(0)$ & $I(0)$ & $I(0)$ \\
\hline & 30 & 0 & 0 & 0 & $19(2)$ & $19(0)$ & 0 & 0 & 0 \\
\hline & 31 & 0 & 0 & 0 & $3(1)$ & $3(0)$ & 0 & 0 & 0 \\
\hline & 32 & 0 & 0 & 0 & 0 & 0 & 0 & 0 & $7(3)$ \\
\hline & 33 & 0 & 0 & 0 & 0 & 0 & 0 & 0 & $17(2)$ \\
\hline & 34 & 0 & 0 & 0 & $\mathrm{I}(0)$ & $I(0)$ & 0 & 0 & 0 \\
\hline & 35 & 0 & 0 & 0 & $\mathrm{I}(0)$ & 0 & 0 & 0 & 0 \\
\hline \multicolumn{10}{|l|}{ HGT-KRTAP } \\
\hline & 6 & $3(0)$ & $3(0)$ & $5(1)$ & $6(0)$ & $6(0)$ & $6(0)$ & 0 & 0 \\
\hline & 7 & $\mathrm{I}(\mathrm{I})$ & $\mathrm{I}(0)$ & $I(0)$ & $\mathrm{I}(0)$ & $\mathrm{I}(0)$ & $\mathrm{I}(0)$ & $I(0)$ & 0 \\
\hline & 8 & $3(2)$ & $3(2)$ & $I(0)$ & $I(0)$ & $\mathrm{I}(0)$ & $I(0)$ & $I(0)$ & $2(0)$ \\
\hline & 19 & $14(5)$ & $10(3)$ & $15(4)$ & $12(1)$ & $12(1)$ & $14(6)$ & 0 & 0 \\
\hline & 20 & $2(0)$ & $2(0)$ & $3(0)$ & $32(0)$ & $21(1)$ & $8(4)$ & $42(6)$ & $9(1)$ \\
\hline & 21 & $4(1)$ & $6(0)$ & $5(0)$ & $4(I)$ & $3(0)$ & $10(0)$ & 0 & $\mathrm{II}(\mathrm{I})$ \\
\hline
\end{tabular}

The number in parentheses indicates the number of disrupted genes. HS-KRTAP and HGT-KRTAP indicate high cysteine and high glycine/tyrosine KRTAP respectively.

ments shared between pairs of nucleotide sequences. We found a large number of KRTAP gene pairs for which gene conversion events are suggested in the high/ultrahigh cysteine subfamilies, but significantly fewer, only 4 pairs, in high glycine-tyrosine subfamilies $\left(\chi^{2}=73.85, \mathrm{p}<<10^{-}\right.$ ${ }^{10}$ ) (summarized in additional file 3 ). The distribution of gene conversion events differs between species, suggesting that different levels of gene conversion occur in each species. For example, 32 gene pairs in rat subfamily 10 suggested evidence for gene conversion, but only 7 pairs were identified for this subfamily in the mouse. The RDP2 program also detected a large number of recombination events within the high cysteine KRTAP genes but fewer in the high glycine/tyrosine genes (additional file 4), and typically suggested that different gene pairs were involved. The identification of different gene pairs by the two methods may reflect differences in how the two programs identify recombination events.
Evidence for concerted evolution was also found in changes in base composition of the genes. Gene conversion is a nonreciprocal recombination process in which a DNA segment of a recipient gene is copied from a donor gene and occurs during the repair of double strand breaks by recombination [52]. Recently, it has been discovered that gene conversion introduces a GC nucleotide bias into sequences, the biased gene conversion (BCG) concept, resulting in the enrichment of GC content in DNA sequences undergoing concerted evolution $[52,53]$ resulting in a positive correlation between rate of gene conversion and GC content. Therefore we examined the GC content of KRTAP coding sequences, which we propose scales with the rate of gene conversion. To evaluate the contribution of concerted evolution, we also scaled the level of gene conversion by distance between paralogs in each subfamily. It has been reported that the frequency of gene conversion correlates negatively with the divergence between gene pairs [54]. Synonymous nucleotide sites are 
Table 2: Amino acid composition of KRTAPs subfamily genes in mammals.

\begin{tabular}{|c|c|c|c|c|c|c|c|c|c|}
\hline HS-KRTAP & subfamily & $C$ & $\mathrm{G}$ & $\mathrm{L}$ & $P$ & $\mathrm{Q}$ & $S$ & $T$ & $Y$ \\
\hline & I & 26.57 & 10.04 & 1.67 & 9.22 & 6.84 & 15.55 & 8.04 & 1.88 \\
\hline & 2 & 29.1 & 4.42 & 1.44 & 14.4 & 6.03 & 10.33 & 9.25 & 0.56 \\
\hline & 3 & 19.93 & 4.72 & 8.01 & 15.6 & 2.9 & 8.53 & 10.84 & 1.53 \\
\hline & 4 & 37.37 & 2.98 & 1 & 10.57 & 5.47 & 16.21 & 7.91 & 0.51 \\
\hline & 5 & 35.86 & 23.67 & 0.1 & 5.01 & 3.39 & 19.25 & 0.65 & 0.27 \\
\hline & 9 & 35.26 & 2.65 & 1.02 & 11.04 & 7.17 & 12.74 & 13.95 & 1.32 \\
\hline & 10 & 27.61 & 2.55 & 3.34 & 13 & 6.1 & 18.76 & 4.62 & 0.52 \\
\hline & 11 & 13.1 & 8.08 & 4.08 & 8.24 & 7.45 & 14.75 & 12.16 & 2.43 \\
\hline & 12 & 22.86 & 2.57 & 2.17 & $13.8 \mid$ & 6.18 & 21.12 & 4.02 & 1.33 \\
\hline & 13 & 11.47 & 10.61 & 5.73 & 7.41 & 4.17 & 21.31 & 5.88 & 7.49 \\
\hline & 17 & 36.06 & 31.44 & 0.26 & 4.49 & 4.23 & 9.91 & 3.17 & 0 \\
\hline & 24 & 9.77 & 5.05 & 7.45 & 9.38 & 3.99 & 17.55 & 7.31 & 7.18 \\
\hline & 25 & 7 & 5.07 & 5.56 & 8.21 & 6.28 & 19.08 & 3.86 & 6.28 \\
\hline & 26 & 11.3 & 9.04 & 8.47 & 11.45 & 4.01 & 18.08 & 5.14 & 3.24 \\
\hline & 27 & 8.71 & 4.07 & 6.59 & 7.81 & 7.81 & 18.06 & 7.73 & 1.38 \\
\hline & 28 & 39.54 & 33.66 & 0.01 & 1.6 & 3.93 & 5.8 & 2.69 & 1.02 \\
\hline & 29 & 16.27 & 6.01 & 3.34 & 11.42 & 8.33 & 16.7 & 7.84 & 2.39 \\
\hline & 30 & 19.35 & 2.07 & 2.43 & 14.56 & 5.07 & 17.12 & 6.19 & 2.15 \\
\hline & 31 & 26.53 & 1.02 & 3.06 & 11.9 & 4.76 & 15.08 & 10.66 & 0.11 \\
\hline & 32 & 38.72 & 3.4 & 1.91 & 16.17 & 4.26 & 10 & 8.94 & 0.21 \\
\hline & 33 & 32.18 & 5.42 & 2.65 & 15.29 & 1.52 & 9.17 & 3.19 & 0.11 \\
\hline & 34 & 50.73 & 4.65 & 0.17 & 9.54 & 11.11 & 4.42 & 8.55 & 0.23 \\
\hline & 35 & 9.19 & 8.38 & 4.32 & 11.08 & 4.05 & 21.62 & 8.11 & 5.68 \\
\hline & 36 & 10.34 & 4.6 & 8.05 & 11.49 & 6.9 & 20.69 & 6.9 & 1.15 \\
\hline \multirow[t]{6}{*}{ HGT-KRTAP } & 6 & $13.6 \mid$ & 40.26 & 4.87 & 0.19 & 0.05 & 7.59 & 0.29 & 22.87 \\
\hline & 7 & 8.81 & 19.16 & 4.79 & 7.28 & 0.19 & 11.49 & 6.13 & 12.26 \\
\hline & 8 & 5.72 & 23.97 & 3.94 & 7.16 & 0 & 8.59 & 2.15 & 20.04 \\
\hline & 19 & 6.07 & 36.52 & 4.22 & 1.38 & 0.33 & 10.8 & 0.33 & 19.96 \\
\hline & 20 & 13.9 & 37.61 & 4.61 & 1.73 & 0.26 & 5.72 & 0.23 & 24.2 \\
\hline & 21 & 17.2 & 36.82 & 0.93 & 1.03 & 0.24 & 12.6 & 0.87 & 20.98 \\
\hline
\end{tabular}

The average amino acid content (\%) of high cysteine (HS) and high glycine/tyrosine (HGT) KRTAP subfamily genes is shown. C (cysteine), G (glycine), L (leucine), P (proine), Q (glutamine), S (serine), T (threonine) and Y (tyrosine) are single letter codes for amino acids that are abundant in some KRTAP proteins.

expected to evolve neutrally and can be used to evaluate the relative evolutionary divergence between pairs of genes. Intriguingly, high cysteine KRTAP genes contain extremely high GC content, and the GC content is negatively correlated with the divergence within the high cysteine KRTAP gene subfamilies (fig. 4). Comparatively, high glycine/tyrosine KRTAP contain relatively lower GC content ( $50 \%)$, and a higher synonymous substitution rate (fig. 4), consistent with the detection of fewer gene conversion events.

Phylogenetic relationships can also suggest sequence homogenization, and potentially uncover the level of gene conversion. In the tree of human and chimpanzee KRTAP protein sequences, large quantities of one-to-one orthologies were identified (additional file 2: figure 9), suggesting that intraspecific gene conversion in the past 5 MYRs ago has not obscured orthologous relationships of the human and chimpanzee genes. The number of these one-to-one orthologies is reduced as phylogenetic dis- tances between species pairs increases (additional file 2: figures 9-15).

More dynamical evolution of high glycine/tyrosine KRTAPs Higher GC content in high cysteine KRTAP compared to high glycine/tyrosine genes reveals that strong concerted evolution is occurring in former, and that they evolve in a more stably manner. Accordingly, we compared the evolutionary dynamics of the two kinds of KRTAPs by calculating the Pearson correlation coefficient of the number of genes within each subfamily between species. As expected, the coefficient value is significantly higher for high cysteine KRTAP than for high glycine/tyrosine genes ( $\mathrm{p}<$ $10^{-4}$ by Wilcoxon signed ranks test) (fig. $5 \mathrm{~A}$ ), and the two groups of coefficient values are positively correlated (fig. 5B). In particular, subfamily 20 evolved with a very dramatic variation in gene numbers, e.g. mouse and opossum have 30 and 42 genes respectively, but humans only have 2. As the number of gene conversion events detected was close to zero, the false positive rate for detecting pos- 


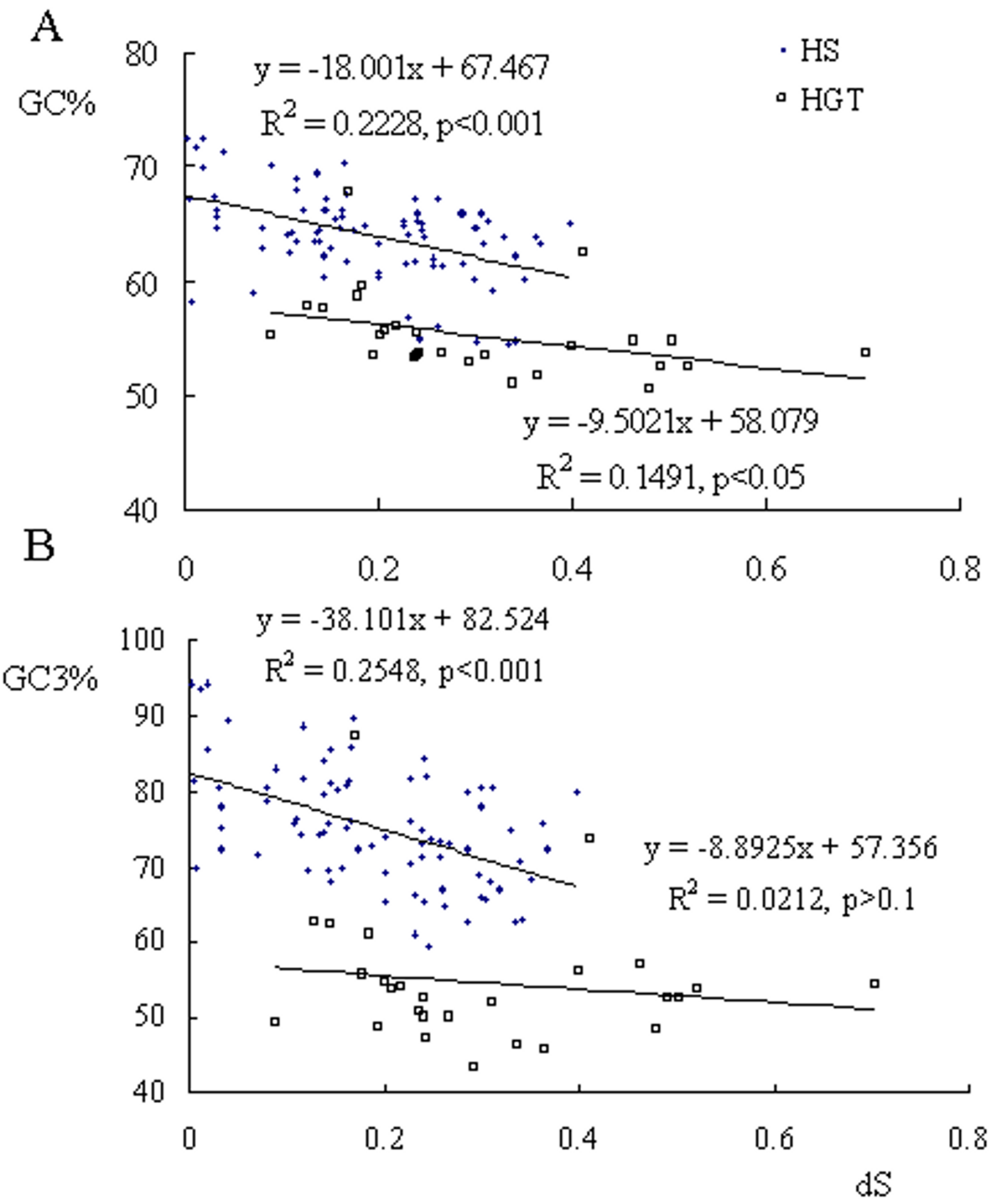

Figure 4

Correlation between GC (Guanine and Cytosine) content and divergence between KRTAP genes. The synonymous substitution rates (dS) among paralogs within each subfamily and codon GC content (GC\%) (A) and third codon GC content (GC3\%) (B) of each subfamily is plotted. Dots and circles represent high cysteine KRTAP (HS) and high glycine-tyrosine KRTAP (HGT), respectively. The linear regression formulae for GC and dS are shown. 


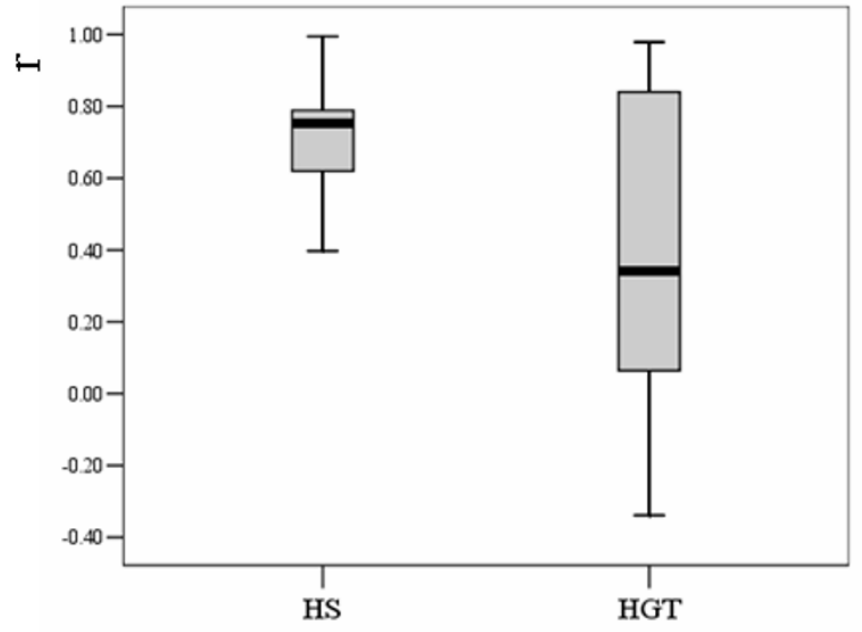

A

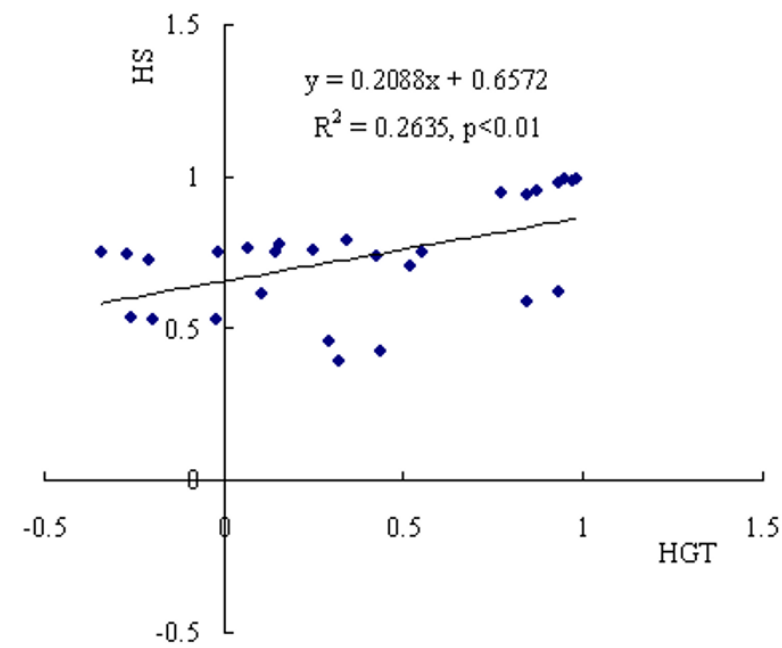

B

\section{Figure 5}

Evolutionary dynamics of KRTAP genes. A comparison of the evolutionary dynamics as evaluated by Pearson correlation coefficient ( $r$ ) of gene numbers of each subfamily between species is shown. A) The coefficient value for the high cysteine KRTAP and high glycine/tyrosine genes is shown with standard errors of the estimates. The correlation coefficient of the high cysteine genes is significantly higher than for the high glycine/tyrosine genes. B) A linear regression of the coefficients between high cysteine KRTAP and high glycine/tyrosine KRTAP genes. The two groups of coefficient values are positively correlated at the $1 \%$ level.

itive selection in subfamily 20 should be very low. Positive selection, which was detected on the rat and opossum lineages by likelihood ratio tests (table 3 ), thus is proposed to be the major force for the dynamic evolution of subfamily 20 and possibly for other high glycine/tyrosine KRTAP genes.

\section{Discussion}

We have described the near-complete inventories of KRTAP genes from the genomes of human, chimpanzee, and rhesus macaque representing primates, mouse and rat representing rodents, dog representing carnivore, opossum representing marsupial, and platypus as a monotreme, and conducted comprehensive analyses of the evolutionary patterns for this gene family, including phylogenetic classification, and the detection of gene conversion.

Among the mammals that we studied, the genomes of each species have members of most of the subfamilies suggesting that the majority of KRTAP gene subfamilies originated and diverged before the mammalian radiation (fig. 1). Accordingly, the mammalian ancestor should also have had a high diversity of KRTAP genes and enjoyed a similar range and spectrum of hair characteristics that is seen in modern mammalian species. The genes for subfamilies that emerged in the early mammals account for about $74 \%$ total number of genes in present mammalian genomes. We advocate that the rapid emergence of the KRTAP gene family correlates with the evolution of mammalian hair and that the rapid emergence of plentiful hair

Table 3: Likelihood ratio tests for positive selection in subfamily 20 by the site-specific models Mla vs M2a within mouse, rat, and opossum.

\begin{tabular}{|c|c|c|c|c|}
\hline & $2 \Delta \mathrm{L}$ & d.f. & Parameters estimated under positive selection model & $\mathrm{p}$-value \\
\hline mouse & 2.819 & 2 & $\begin{aligned} P_{0} & =0.686, P_{1}=0.000, P_{2}=0.314 \\
\omega_{0} & =0.107, \omega_{1}=1.000, \omega_{2}=1.480\end{aligned}$ & 0.244 \\
\hline rat & 13.910 & 2 & $\begin{aligned} P_{0}=0.657, P_{1} & =0.280, P_{2}=0.064, \\
\omega_{0}=0.108, \omega_{1} & =1.000, \omega_{2}=13.370\end{aligned}$ & $9.54 \mathrm{E}-04$ \\
\hline opossum & 18.575 & 2 & $\begin{aligned} \mathrm{P}_{0} & =0.535, \mathrm{P}_{1}=0.41 \mathrm{I}, \mathrm{P}_{2}=0.054 \\
\omega_{0} & =0.096, \omega_{1}=1.000, \omega_{2}=6.894\end{aligned}$ & $9.26 \mathrm{E}-05$ \\
\hline
\end{tabular}


contributed to the successful radiation of homothermal mammals by helping them to retain body heat since hair acts as an insulator [13]. In contrast, Homo sapiens has recently lost body hair function, presumably because humans can obtain heat and can keep cold out by using clothing. Despite a lack of hair, humans actually have a similar density of hair follicles to apes [15], which possibly explains why human do not have a significant fewer number of KRTAP genes. Perhaps, the changes in human hair are due to the reduction in expression of the KRTAP genes. In contrast to humans, rodents have an expanded KRTAP gene family. Perhaps, mouse and rat need more hair as they are adapted to the nocturnal environment. Despite the proposed similar range and diversity of hair characteristics in the ancestor of mammals, the current traits, and content, of hair likely diverged significantly from their ancestral characteristics as KRTAP sequences have diverged dramatically among species due to gene conversion.

Both gene conversion and unequal crossing over have occurred during the evolution of the KRTAP. The evolution of several KRTAP gene subfamilies, such as subfamilies 1, 2 and 3 fit well with a model of punctuated equilibrium (table 1), where morphological divergence as well as speciation occurs in a burst-like manner with rapid evolutionary change followed by long periods of constancy [55]. These KRTAP genes show evidence for fewer gene duplication or loss events, suggesting that a low level of unequal crossing over has occurred within these subfamilies, and that gene conversion may predominate. In addition, the syntenic arrangement of genes of these subfamilies has not been disturbed by post-duplication rearrangement events, suggesting a strong constraint has been exerted upon their distribution. In contrast, other KRTAP genes, such as subfamilies 4 and 5 (table 1 ) have evolved relatively dynamically likely including unequal crossing over as changes in the copy number of this subfamily is observed between species.

Changes in gene numbers within subfamilies between mammals may explain differences in the observed hair morphology between species. No genes of subfamily 9 were identified in opossum or platypus, suggesting that this subfamily originated after the divergence of placental and marsupial mammals. In a similar manner, genes of subfamily 12 emerged before the divergence of marsupials but after the divergence from monotremes (fig. 1). Intriguingly, subfamily 13 has been lost on the marsupial lineage, and the subfamilies 24, 26 and 27 which are adjacent to subfamily 13 in the genome, are also not found in the opossum genome. We used Mapviewer from NCBI to identify genes flanking this cluster in the human genome and searched the opossum genome using BLAST to identify an orthologous genomic region. An ortholog of the human gene that flanks the human KRTAP genes is only about $13 \mathrm{kbp}$ away from the remainder of the KRTAP cluster in the opossum genome, which indicates the loss of this region in the opossum was due to a deletion event. Subfamily 30, which is a member of the ultra-high sulfur ( $50 \%)$ group, along with subfamily 34 are unique to rodents, thus may be partially responsible for the unique characteristics of hair in rodents. Subfamily 35 is mousespecific, while subfamilies 32 and 33 are platypus-specific, which could account for species-specific hair characteristics.

The high-glycine/tyrosine (HGT) gene repertoire evolve more dynamically within mammals with increased levels of pseudogenization (fig. 1), for example, mice possesses 56 genes, while primates have considerably fewer genes with only 27 and 25 genes in human and chimpanzee respectively. The gene number in platypus is likely to be underestimated because HGT cluster in platypus is shorter than that of other mammals (only about $100 \mathrm{kbp}$ in platypus, but $\sim 500 \mathrm{kbp}$ in human, $800 \mathrm{kbp}$ in mouse, and 350 kbp in opossum), and the incomplete nature of this genome sequence. However, the dynamics of HGT subfamilies does not appear to be due to unequal crossing over, as unequal crossing over should also generate a GC content bias that is not observed in these genes (personal communication, Gabriel Marais).

Tandemly arrayed paralogous genes with similar function can provide combinatorial complexity to biological diversity [56]. This extraordinary evolutionary feature has been observed in many multigene families responsible for processes that face enormous external signals. For instance, the sensory system such as the olfactory receptor, vomeronasal receptor and sweet/umami receptor, bitter receptor genes, require a huge combination of diverse receptors for the diverse ligands they encounter in a tremendous range of molecular environments [57]. Another classic example is the immunoglobulin and T-cell receptor protein superfamily which use recombination to generate large quantities of antigen recognition complexes to allow an immune responses to rapidly evolving pathogens [58]. We therefore speculate that an analogous process occurs within the KRTAP gene family, where the KRTAP and keratin proteins have combined in unique combinations to generate the high diversity of hair phenotypes that are observed both between and within species, and even within individuals.

\section{Conclusion}

We have described the near-complete inventories of KRTAP genes in eight mammalian genomes. We found that the KRTAP family was unique to mammals, KRTAP gene repertoire was expanded in rodents, and surprisingly, humans had a similar number of genes as other primates, 
inconsistent with the hairlessness of humans. The high glycine-tyrosine KRTAP genes have evolved more dynamically, with fewer gene conversion events and thus have a lower GC content compared with high cysteine KRTAPs. We propose that the mammalian ancestor should have a diverse KRTAP gene repertoire, and that hair content characteristics have evolved and diverged rapidly among mammals because of rapid divergent evolution of KRTAPs between species caused by concerted evolution.

\section{Methods}

\section{Retrieval of sequences}

Some KRTAP genes have previously been annotated to possess introns, which generally complicates gene prediction and identification. All of the intron-containing KRTAP genes have short introns, and the sequences of these introns are similar to the repeated regions found within the exons, and many are predicted to be alternatively spiced. All of the introns could be included in a primary transcript that can be translated in-frame with the coding exons, they just have longer repetitive regions. Therefore, we hypothesize that all of the KRTAP genes can generate an mRNA sequence that is intron-less.

We identified KRTAP gene repertoires in the genome assemblies from human (Homo sapiens) (build36.2), chimpanzee (Pan troglodytes) (build2.1), rhesus macaque (Macaca mulatta) (build1.1), mouse (Mus musculus) (build36.1), rat (Rattus norvegicus) (RGSC v3.4), dog (Canis familiaris) (build2.1), opossum (Monodelphis domesticus) (MonDom5) and platypus (Ornithorhynchus anatinus) (build1.1). We used the BLASTn algorithm [59] to search these genomes using all known human KRTAP genes as queries. Each newly identified putative KRTAP gene was used as a query using BLAST http:// blast.ncbi.nlm.nih.gov/Blast.cgi against the non-redundant GenBank database to check whether their best hit was a KRTAP gene. The chicken (Gallus gallus) (Build 2.1), zebrafish (Danio rerio) genomes (Zv6) in NCBI [60], lizard (Anolis carolinensis) genome at UCSC http:// genome.ucsc.edu/ and the Xenopus tropicalis genome at JGI [61] genomes were also searched using BLAST for KRTAPlike sequences. Sequences that possessed an interrupting stop codons and/or frame-shifts caused by insertions or deletions were denoted as pseudogenes.

\section{Phylogenetic reconstruction}

In order to classify the members of the KRTAP gene family, protein sequences were used to construct phylogenetic trees using the neighbor-joining method with p-distances with MEGA3.0 http://www.megasoftware.net[62] after alignment with ClustalW http://www.ebi.ac.uk/Tools/ clustalw/index.html[63]. The reliability of the trees was evaluated by the interior branch tests with 1,000 replications.

\section{Detection of recombination}

We employed the GeneConv program http:// www.math.wustl.edu/ sawyer/geneconv/[51] to identify potential gene conversion events in the KRTAP coding sequences. Gene conversion is a process where a segment of DNA from one allele of a gene is copied and replaces the sequence in another allele or gene. Accordingly, GeneConv extends a method previously described by [51] and detects this process by identifying shared fragments between pairs of sequences. Global Bonferroni corrected P values were calculated to evaluate the statistical significance of the observed fragment lengths and are compared to a simulated distribution $(10,000$ iterations) of the same number of sequences with similar variation. Lower $P$ values suggest a greater probability that a gene conversion event has occurred. GeneConv has a significant limitation in that it is unable to distinguish between gene conversion and unequal crossing over events, but to date no other effective bioinformatic method have been described that can distinguish between these two types of events. We therefore, can not distinguish gene conversion and unequal crossing over.

The divergence among paralogs could also reflect the level of conversion which can homogenize paralogs. Nucleotide sequences were back-translated from protein sequences after alignment by ClustalW [63]. Alignments were modified manually if necessary. Approximate synonymous substitution rate (Ks) values within subfamilies were calculated by the modified Nei-Gojobori (p-distance) method with a transition/transversion ratio of 2 [64].

Recombination events were also detected using the RDP2 software package http://darwin.uvigo.es/rdp/ rdp.html[65]. Evidence for recombination was detected by running RDP, BootScan, MaxChi and Chimaera with 1,000 permutations. Sequences were considered linear. The highest acceptable P value cut-off was set to 0.01 . Bonferroni correction was employed.

\section{Adaptive evolution analysis}

The site-specific models M1a and M2a implemented in PAML http://abacus.gene.ucl.ac.uk/software/paml.html were used to detect potentially positively selected sites in the subfamily [66-68]. Considering the high false positive rate of likelihood ratio tests, particularly when there is frequent recombination $[69,70]$, we only detected positive selection in subfamily 20 , a family in which gene conversion does not appear to occur and has expanded dramatically on the mouse, rat and opossum lineages.

\section{Statistical analysis}

We calculated the potential number of gene pairs where gene conversion could occur by $\sum \mathrm{N}_{\mathrm{ij}}\left(\mathrm{N}_{\mathrm{ij}}-1\right) / 2$, where $\mathrm{N}_{\mathrm{ij}}$ is 
the intact gene numbers in subfamily $i$ within species $j$, and $\mathrm{N}$ must be higher than 2 for gene conversion to be detected by the GeneConv program. The chi test was used to detect statistical significance in the difference in number of gene conversion events occurring between high cysteine and high glycine/tyrosine KRTAP. The Pearson correlation coefficient of the number of genes in each subfamily was determined for pairs of species (table 1 ). The evolutionary dynamics of the high cysteine and high glycine/tyrosine KRTAP genes was evaluated by comparing the values of the Pearson correlation coefficients.

\section{Authors' contributions}

DDW, DMI and YPZ designed the research and outlined the manuscript together, and DDW drafted the manuscript. ALL authors have read and approved the final manuscript.

\section{Additional material}

\section{Additional file 1}

table 1. KRTAP genes in the human, chimpanzee, rhesus macaque, dog, mouse, rat, opossum, and platypus genomes.

Click here for file

[http://www.biomedcentral.com/content/supplementary/1471-

2148-8-241-S1.xls]

\section{Additional file 2}

figure 1-figure 17. Figure 1-Figure 16 are the phylogenetic trees of high/ ultrahigh cysteine KAPs of human (Figure 1), chimpanzee (Figure 2), rhesus macaque(figure 3), dog (figure 4), mouse (figure 5), rat (figure 6), opossum (figure 7), platypus(figure 8), human and chimpanzee (figure 9), human and rhesus macaque (figure 10), human and dog (figure 11), human and mouse (figure 12), human and rat (figure 13), human and opossum (figure 14), human and platypus (figure 15), mouse and rat (figure 16). Figure 17 is the phylogenetic tree of high glycine/tyrosine KRTAPs. $h$ represents human, $c$ is chimpanzee, rh is rhesus macaque, $d$ dog, m-mouse, $r$ is rat, $o$ is opossum, and $p$ is platypus. The values on the branches are reliabilities, which are evaluated by the interior branch tests with 1,000 replications. Only values higher than $50 \%$ are noted.

Click here for file

[http://www.biomedcentral.com/content/supplementary/1471-

2148-8-241-S2.pdf]

\section{Additional file 3}

table 2. Pairs of genes with significant statistical support for gene conversion. The significances are calculated by Bonferroni-corrected method. Click here for file

[http://www.biomedcentral.com/content/supplementary/14712148-8-241-S3.doc]

\section{Additional file 4}

table 3. Results of recombination detection by RDP2 program with algorithms: RDP, BootScan, MaxChi and Chimaera with 1,000 permutations. Sequences were considered linear. The highest acceptable P value cut-off was set to 0.01, and the Bonferroni correction was employed. The numbers are the unique events (recombination signals).

Click here for file

[http://www.biomedcentral.com/content/supplementary/14712148-8-241-S4.doc]

\section{Additional file 5}

human HS-KRTAP aligned protein sequences. The KRTAP5-12 protein sequence was not used for alignment as it is too short.

Click here for file

[http://www.biomedcentral.com/content/supplementary/1471-

2148-8-241-S5.fas]

\section{Additional file 6}

Aligned human HGT-KRTAP protein sequences.

Click here for file

[http://www.biomedcentral.com/content/supplementary/14712148-8-241-S6.fas]

\section{Acknowledgements}

We are grateful to the invaluable suggestions and help with the classification of genes from Dr. Michael A. Rogers at the Section of Normal and Neoplastic Epidermal Differentiation, German Cancer Research Center, Heidelberg, Germany, and the kind help of Dr Matt Wright from the HUGO Gene Nomenclature Committee. We thank Dr. Peng Shi, Ms. Jing He, and Mr. Guo-Dong Wang for comments. This work was supported by grants from the National Basic Research Program of China (973 Program, 2007CB4 I I 600), the National Natural Science Foundation of China (30621092, 30430I I0), and Bureau of Science and Technology of Yunnan Province.

\section{References}

I. Hughes AL: Adaptive evolution of genes and genomes. Oxford University Press US; 1999.

2. Niimura $Y$, Nei M: Evolutionary dynamics of olfactory receptor genes in fishes and tetrapods. Proc Natl Acad Sci USA 2005, 102(I7):6039-6044.

3. Niimura $Y$, Nei M: Evolutionary dynamics of olfactory and other chemosensory receptor genes in vertebrates. J Hum Genet 2006, 5 I (6):505-5I7.

4. Niimura $Y$, Nei M: Extensive gains and losses of olfactory receptor genes in mammalian evolution. PLOS ONE 2007, 2(8):e708.

5. Grus WE, Shi P, Zhang J: Largest vertebrate vomeronasal type I receptor (VIR) gene repertoire in the semi-aquatic platypus. Mol Biol Evol 2007, 24:2153-2I57.

6. Grus WE, Shi P, Zhang Y, Zhang J: Dramatic variation of the vomeronasal pheromone receptor gene repertoire among five orders of placental and marsupial mammals. Proc Natl Acad Sci USA 2005, 102(16):5767-5772.

7. Shi $P$, Zhang : Comparative genomic analysis identifies an evolutionary shift of vomeronasal receptor gene repertoires in the vertebrate transition from water to land. Genome Res 2007, 17(2): 166

8. Young JM, Trask BJ: V2R gene families degenerated in primates, dog and cow, but expanded in opossum. Trends Genet 2007, 23(5):2I2-2I5

9. Fischer A, Gilad Y, Man O, Pääbo S: Evolution of bitter taste receptors in humans and apes. Mol Biol Evol 2005, 22(3):432-436.

10. Parry CM, Erkner A, le Coutre J: Divergence of T2R chemosensory receptor families in humans, bonobos, and chimpanzees. Proc Natl Acad Sci USA 2004, I 0 I (4 I): I 4830- I 4834.

II. Shi P, Zhang J, Yang H, Zhang Y: Adaptive diversification of bitter taste receptor genes in mammalian evolution. Mol Biol Evol 2003, 20(5):805-8|4.

12. Shi P, Zhang J: Contrasting modes of evolution between vertebrate sweet/umami receptor genes and bitter receptor genes. Mol Biol Evol 2006, 23(2):292-300.

13. Maderson PFA: Mammalian skin evolution: a reevaluation. Exp Derm 2003, I 2(3):233-236. 
14. Bergman J: Why mammal body hair is an evolutionary enigma. Creation Research Society Quarterly 2004, 40:240-243.

15. Schwartz GG, Rosenblum LA: Allometry of primate hair density and the evolution of human hairlessness. Am J phys Anthrop I98I, 55:9-12.

16. Wheeler PE: The evolution of bipedality and loss of functional body hair in hominids. J Hum Evol 1984, I3(1):91-98.

17. Alibardi L: Fine structure and immunocytochemistry of monotreme hairs, with emphasis on the inner root sheath and trichohyalin-based cornification during hair evolution. J Morphol 2004, 26 I(3):345-363.

18. Alibardi L: Fine structure of marsupial hairs, with emphasis on trichohyalin and the structure of the inner root sheath. J Morphol 2004, 26 I (3):390-402.

19. Alibardi L: Comparative aspects of the inner root sheath in adult and developing hairs of mammals in relation to the evolution of hairs. J Anat 2004, 205(3): 179-200.

20. Rogers MA, Winter H, Wolf C, Heck M, Schweizer J: Characterization of a 190-kilobase pair domain of human type I hair keratin genes. J Biol Chem 1998, 273(4I):26683-2669I.

21. Rogers MA, Winter H, Langbein L, Wolf C, Schweizer J: Characterization of a $\mathbf{3 0 0} \mathrm{kbp}$ region of human DNA containing the type II hair keratin gene domain. I Invest Dermatol 2000, I I 4(3):464-472

22. Hesse M, Zimek A, Weber K, Magin TM: Comprehensive analysis of keratin gene clusters in humans and rodents. Eur J Cell Biol 2004, 83(I): 19-26.

23. Rogers MA, Langbein L, Praetzel-Wunder S, Winter H, Schweizer I: Human hair keratin-associated proteins (KAPs). Int Rev Cyto 2006, 25 I:209-263.

24. Langbein L, Rogers MA, Winter H, Praetzel S, Beckhaus U, Rackwitz $H-R$, Schweizer J: The catalog of human hair keratins. I. Expression of the nine type I members in the hair follicle. J Biol Chem 1999, 274(28): I9874- 9884

25. Langbein L, Rogers MA, Winter H, Praetzel S, Schweizer J: The catalog of human hair keratins. II. Expression of the six type II members in the hair follicle and the combined catalog of human type I and II keratins. J Biol Chem 200I, 276(37):35|23-35I32.

26. Powell BC, Nesci A, Rogers GE: Regulation of keratin gene expression in hair follicle differentiation. Ann NY Acad Sci 1991, 642: I-20.

27. Powell BC, Arthur J, Nesci A: Characterization of a gene encoding a cysteine-rich keratin associated protein synthesized late in rabbit hair follicle differentiation. Differentiation 1995 , 58(3):227-232.

28. Powell BC, Rogers GE: The role of keratin proteins and their genes in the growth, structure and properties of hair. In Formation and Structure of Human Hair Edited by: Jolles PZH, Höcker $\mathrm{H}$. Basel:Birkhäuser Verlag; 1997:59-|48.

29. Rogers MA, Winter H, Langbein L, Wollschlager A, Praetzel-Wunder $S$, Jave-Suarez LF, Schweizer J: Characterization of human KAP24. I, a cuticular hair keratin-associated protein with unusual amino-acid composition and repeat structure. Invest Dermatol 2007, I 27: I I 97- I 204.

30. Rogers MA, Langbein L, Winter H, Ehmann C, Praetzel S, Korn B, Schweizer J: Characterization of a cluster of human high/ultrahigh sulfur keratin-associated protein genes embedded in the type I keratin gene domain on chromosome I7q I 2-2 I. Biol Chem 200I, 276(22): 19440-1945I.

31. Rogers MA, Langbein L, Winter H, Ehmann C, Praetzel S, Schweizer $\mathrm{J}$ : Characterization of a first domain of human high glycinetyrosine and high sulfur keratin-associated protein (KAP) genes on chromosome 2lq22. I Biol Chem 2002, 277(50):48993-49002.

32. Rogers MA, Langbein L, Winter H, Beckmann I, Praetzel S, Schweizer J: Hair keratin associated proteins: characterization of a second high sulfur KAP gene domain on human chromosome 21. J Invest Dermatol 2004, I 22: I47-I58.

33. Shibuya K, Obayashi I, Asakawa S, Minoshima S, Kudoh J, Shimizu N: A cluster of 21 keratin-associated protein genes within introns of another gene on human chromosome 2 Iq22. 3. Genomics 2004, 83(4):679-693.

34. Yahagi S, Shibuya K, Obayashi I, Masaki H, Kurata Y, Kudoh J, Shimizu $\mathrm{N}$ : Identification of two novel clusters of ultrahigh-sulfur ker- atin-associated protein genes on human chromosome II. Biochem Biophys Res Commun 2004, 3 I 8:655-664.

35. International Human Genome Sequencing Consortium: Initial sequencing and analysis of the human genome. Nature 200I, 409:860-921.

36. The Chimpanzee Sequencing and Analysis Consortium: Initial sequence of the chimpanzee genome and comparison with the human genome. Nature 2005, 437:69-87.

37. Rhesus Macaque Genome Sequencing and Analysis: Evolutionary and biomedical insights from the rhesus macaque genome. Science 2007, 3 16:222-234.

38. Mouse Genome Sequencing Consortium: Initial sequencing and comparative analysis of the mouse genome. Nature 2002, 420:520-562.

39. Rat Genome Sequencing Project Consortium: Genome sequence of the Brown Norway rat yields insights into mammalian evolution. Nature 2004, 428:493-52I.

40. Lindblad-Toh K, Wade CM, Mikkelsen TS, Karlsson EK, Jaffe DB, Kamal M, Clamp M, Chang JL, Kulbokas EJ, Zody MC, Mauceli E, Xie X, Breen M, Wayne RK, Ostrander EA, Ponting CP, Galibert F, Smith DR, dejong PJ, Kirkness E, Alvarez P, Biagi T, Brockman W, Butler J, Chin C-W, Cook A, Cuff J, Daly MJ, DeCaprio D, Gnerre S, Grabherr M, Kellis M, Kleber M, Bardeleben C, Goodstadt L, Heger A, Hitte C, Kim L, Koepfli K-P, Parker HG, Pollinger JP, Searle SMJ, Sutter NB, Thomas R, Webber C, Lander ES: Genome sequence, comparative analysis and haplotype structure of the domestic dog. Nature 2005, 438:803-819.

4I. Mikkelsen TS, Wakefield MJ, Aken B, Amemiya CT, Chang JL, Duke S, Garber M, Gentles AJ, Goodstadt L, Heger A, Jurka J, Kamal M, Mauceli E, Searle SMJ, Sharpe T, Baker ML, Batzer MA, Benos PV, Belov K, Clamp M, Cook A, Cuff J, Das R, Davidow L, Deakin JE, Fazzari MJ, Glass JL, Grabherr M, Greally JM, Gu W, Hore TA, Huttley GA, Kleber M, Jirtle RL, Koina E, Lee JT, Mahony S, Marra MA, Miller RD, Nicholls RD, Oda M, Papenfuss AT, Parra ZE, Pollock DD, Ray DA, Schein JE, Speed TP, Thompson K, VandeBerg JL, Wade CM, Walker JA, Waters PD, Webber C, Weidman JR, Xie X, Zody MC, Graves JAM, Ponting CP, Breen M, Samollow PB, Lander ES, LindbladToh K: Genome of the marsupial Monodelphis domestica reveals innovation in non-coding sequences. Nature 2007, 447:167-177

42. Warren WC, Hillier LW, Graves JAM, Birney E, Ponting CP, Grützner F, Belov K, Miller W, Clarke L, Chinwalla AT, Yang S-P, Heger A, Locke DP, Miethke P, Waters PD, Veyrunes F, Fulton L, Fulton B, Graves T, Wallis J, Puente XS, López-Otín C, Ordóñez GR, Eichler EE, Chen L, Cheng Z, Deakin JE, Alsop A, Thompson K, Kirby P, Papenfuss AT, Wakefield MJ, Olender T, Lancet D, Huttley GA, Smit AFA, Pask A, Temple-Smith P, Batzer MA, Walker JA, Konkel MK, Harris RS, Whittington CM, Wong ESW, Gemmell NJ, Buschiazzo E, Jentzsch IMV, Merkel A, Schmitz J, Zemann A, Churakov G, Kriegs JO, Brosius J, Murchison EP, Sachidanandam R, Smith C, Hannon G], Tsend-Ayush E, McMillan D, Attenborough R, Rens W, FergusonSmith M, Lefèvre CM, Sharp JA, Nicholas KR, Ray DA, Kube M, Reinhardt R, Pringle TH, Taylor J, Jones RC, Nixon B, Dacheux J-L, Niwa H, Sekita Y, Huang X, Stark A, Kheradpour P, Kellis M, Flicek P, Chen Y, Webber C, Hardison R, Nelson J, Hallsworth-Pepin K, Delehaunty K, Markovic C, Minx P, Feng Y, Kremitzki C, Mitreva M, Glasscock J, Wylie T, Wohldmann P, Thiru P, Nhan MN, Pohl CS, Smith SM, Hou S, Renfree MB, Mardis ER, Wilson RK: Genome analysis of the platypus reveals unique signatures of evolution. Nature 2008, 453(71 92): $175-183$.

43. Kariya N, Shimomura $Y$, Ito M: Size polymorphisms in the human ultrahigh sulfur hair keratin-associated protein 4 , KAP4, gene family. J Invest Dermatol 2005, I 24: I III-1 I I8.

44. Rogers MA, Schweizer J: Human KAP genes, only the half of it? extensive size polymorphisms in hair keratin-associated protein genes. J Invest Dermatol 2005, I 24(6):vii-ix.

45. Shimomura Y, Aoki N, Schweizer J, Langbein L, Rogers MA Winter $\mathrm{H}$, Ito M: Polymorphisms in the human high sulfur hair keratin-associated protein I, KAPI, gene family. J Biol Chem 2002, 277(47):45493-4550I

46. Huntley S, Baggott DM, Hamilton AT, Tran-Gyamfi M, Yang S, Kim J, Gordon L, Branscomb E, Stubbs L: A comprehensive catalog of human KRAB-associated zinc finger genes: Insights into the evolutionary history of a large family of transcriptional repressors. Genome Res 2006, 16(5):669-677. 
47. Nei M, Rooney AP: Concerted and birth-and-death evolution of multigene families. Annu Rev Genet 2005, 39: I2I-I52.

48. [http://www.genenames.org/].

49. Hamilton AT, Huntley S, Tran-Gyamfi M, Baggott DM, Gordon L, Stubbs L: Evolutionary expansion and divergence in the ZNF9I subfamily of primate-specific zinc finger genes. Genome Res 2006, I6(5):584-594.

50. Niimura $Y$, Nei M: Evolution of olfactory receptor genes in the human genome. Proc Natl Acad Sci USA 2003, I 00(2I): I 2235-12240.

51. Sawyer S: Statistical tests for detecting gene conversion. Mol Biol Evol 1989, 6(5):526-538.

52. Marais G: Biased gene conversion: implications for genome and sex evolution. Trends Genet 2003, I9(6):330-338.

53. Galtier N: Gene conversion drives GC content evolution in mammalian histones. Trends Genet 2003, 19(2):65-68.

54. Drouin G: Characterization of the gene conversions between the multigene family members of the yeast genome. J Mol Evol 2002, 55(I): 14-23.

55. Gould SJ, Eldredge N: Punctuated equilibrium comes of age. Nature 1993, 366(6452):223-227.

56. Noonan JP, Grimwood J, Schmutz J, Dickson M, Myers RM: Gene conversion and the evolution of protocadherin gene cluster diversity. Genome Res 2004, I 4(3):354-366.

57. Mombaerts P: Genes and ligands for odorant, vomeronasal and taste receptors. Nat Rev Neurosci 2004, 5(4):263-278.

58. Flajnik MF: Comparative analyses of immunoglobulin genes: surprises and portents. Nat Rev Immunol 2002, 2(9):688-698.

59. Altschul SF, Madden TL, Schaffer AA, Zhang J, Zhang Z, Miller W, Lipman DJ: Gapped BLAST and PSI-BLAST: a new generation of protein database search programs. Nucleic Acids Res 1997, 25(I7):3389-3402.

60. [http://www.ncbi.nlm.nih.gov/].

61. [http://genome.jgi-psf.org/Xentr4/Xentr4.home.html].

62. Kumar S, Tamura K, Nei M: MEGA3. 0: Integrated software tot molecular evolutionary genetics analysis and sequence alignment. Brief Bioinlbrm 2000, 4(5): 150-163.

63. Thompson JD, Higgins DG, Gibson TJ: CLUSTALW: improving the sensitivity of progressive multiple sequence alignment through sequence weighting, position-specific gap penalties and weight matrix choice. Nucleic Acids Res 1994, 22:4673-4680.

64. Rosenberg MS, Subramanian S, Kumar S: Patterns of transitional mutation biases within and among mammalian genomes. Mol Biol Evol 2003, 20(6):988-993.

65. Martin DP, Williamson C, Posada D: RDP2: recombination detection and analysis from sequence alignments. Bioinformatics 2005, 2 I (2):260-262.

66. Yang Z: PAML: a program package for phylogenetic analysis by maximum likelihood. Comput Appl Biol Sci 1997, 13:555-556.

67. Yang Z: Likelihood ratio tests for detecting positive selection and application to primate lysozyme evolution. Mol Biol Evol 1998, I5(5):568-573.

68. Nielsen R, Yang Z: Likelihood models for detecting positively selected amino acid sites and applications to the HIV-I envelope gene. Genetics 1998, I48(3):929-936.

69. Anisimova $M$, Nielsen $R$, Yang Z: Effect of recombination on the accuracy of the likelihood method for detecting positive selection at amino acid sites. Genetics 2003, I 64(3): I229-1236.

70. Zhang J, Nielsen R, Yang Z: Evaluation of an improved branchSite likelihood method for detecting positive selection at the molecular level. Mol Biol Evol 2005, 22(1 2):2472-2479.
Publish with Biomed Central and every scientist can read your work free of charge

"BioMed Central will be the most significant development for disseminating the results of biomedical research in our lifetime. "

Sir Paul Nurse, Cancer Research UK

Your research papers will be:

- available free of charge to the entire biomedical community

- peer reviewed and published immediately upon acceptance

- cited in PubMed and archived on PubMed Central

- yours - you keep the copyright
BioMedcentral 